\title{
OS DISCURSOS DA EJA EM FLORIANÓPOLIS: CIDADANIA, TRABALHO E CONTROLE
}

\author{
THE DISCOURSES OF ADULT EDUCATION IN FLORIANÓPOLIS: \\ CITIZENSHIP, WORK AND CONTROL
}

Samoel Valdemiro Raulino

Bacharel em Letras - Português pela Universidade Federal de Santa Catarina samoel.raulino@gmail.com

Atilio Butturi Junior Docente do Programa de Pós-graduação em Linguística e do Departamento de Língua e Literatura Vernáculas da Universidade Federal de Santa Catarina atilio.butturi@ufsc.br

Resumo: Este trabalho tem como objetivo analisar os discursos de três documentos legais que regem a Educação de Jovens e Adultos (EJA) enquanto modalidade de ensino no sistema municipal de ensino de Florianópolis, entendendo-os segundo a discussão dos dispositivos de governo, conforme os debates foucaultianos. Inicialmente, apresentamos algumas problematizações de ordem metodológica. Adiante, elaboramos um panorama discursivo dos discursos educacionais sobre a escolarização de jovens e adultos no cenário histórico brasileiro - partindo da época colonial até hoje. Depois disso, traçamos as análises dos documento da EJA, interrogando-os segundo os discursos de formação para o trabalho, cidadania e controle. Concluímos que permanece no discurso da EJA uma assunção do mito da educação e de um poder positivo que cinde formas de subjetividade a partir da necessidade de formação - controlada e disciplinada - dos educandos.

Palavras-chave: Escolarização de jovens e adultos; Discurso; Dispositivo.

Abstract: This paper aims to analyzes the discourses of three legal documents of Adult Education as a teaching modality in Florianópolis educational municipal system, in the light of the concept of governance apparatus, according to Foucauldian discussions. Firstly, we present some methodological issues. Secondly, we develop a discursive overview of the educational discourses on Adult Education in the Brazilian historical setting - starting from the colonial period until today. After that, we draw an analysis of those 
official documents concerning Adult Education, examining them according to the discourses of work, citizenship and control. We conclude that an assumption of the myth of education and of a positive power that cleaves forms of subjectivity from the need for a controlled and disciplined training of the students still remains in the discourse of Adult Education.

Keywords: Adult education; Discourse; Apparatus.

\section{Introdução}

Iniciemos com Foucault, portanto, lendo a quarta parte de Vigiar e Punir, Prisão. Perto do encerramento de sua arqueologia do poder de criminalização e de encarceramento, o francês faz notar que o dispositivo da prisão nasceu permeado de críticas, tanto de seus princípios quanto de seus métodos, que sobejavam já no século XIX. No entanto, Foucault (2013a, p. 262) faz uma espécie de exigência: "O atestado de que a prisão fracassa em reduzir os crimes deve talvez ser substituído pela hipótese de que a prisão conseguiu muito bem produzir a delinquência [...] produzir os delinquentes, meio aparentemente marginalizado, mas centralmente controlado [...]”.

O excerto foucaultiano aponta para uma problemática axial, qual seja, a do paradoxal êxito de um fracasso. Dito de outro modo, o que está em jogo é menos uma tecnologia de justiça, mas uma tecnologia de controle e docilização dos sujeitos, cujo sucesso reside na produção ubíqua da normalidade (em detrimento da correção e da inclusão que, em tese, a prisão pressupunha) - a prisão, nesse caso, opera segundo a ordem de um dispositivo que suplanta os seus próprios limites e que se espraia sobre toda sorte de relações entre os sujeitos e o poder, com os chamados "[...] avanços dos dispositivos de normalização [...]”. (FOUCAULT, 2013a, p. 290).

Voltemo-nos para as questões que norteiam o presente trabalho, quais sejam, as relacionadas à escolarização de jovens e adultos no município de Florianópolis, Santa Catarina. Como se sabe, Foucault não analisou o discurso da educação propriamente, muito menos a escolarização de jovens e adultos. Todavia, suas análises visam as relações de poder e objetificação dos sujeitos e, por conseguinte, muitas vezes a educação formal e a escola aparecem em seus textos. No mesmo Vigiar e Punir, a pergunta que reaparece por diversas vezes diz respeito, sobretudo, ao papel normalizador da escola: "Devemos 
ainda nos admirar que a prisão se pareça com as fábricas, com as escolas, com os quartéis, com os hospitais, e todos se pareçam com as prisões?” (FOUCAULT, 2013a, p. 214).

Os esforços de analisar a educação e o cenário educacional brasileiro por meio de reflexões foucaultianas não é algo inédito, nem diminuto. Para Fischer (2003), há pelo menos 20 anos, alguns estudiosos da educação, no Brasil, propõem lançar seus olhares ao campo da educação sob a égide dos estudos de Foucault. Segundo ela, como justificativa de direcionar as pesquisas educacionais, os estudos arqueogenealógicos discutem "as práticas da vigilância na escola, a construção disciplinar dos currículos, as relações de poder na [sic] espaço da sala de aula, a produção de sujeitos confidentes”. (FISCHER, 2003, p. 372). ${ }^{1}$

Dessa perspectiva foulcaultiana, retomamos e circunscrevemos nosso objetivo: analisar relações de poder-saber materializadas nos discursos dos documentos oficiais apontados como corpus desta pesquisa, entendidos como procedimentos fulcrais de constituição da modalidade de Educação de Jovens e Adultos na cidade de Florianópolis, Santa Catarina. A hipótese a ser defendida é de que há uma prática de objetivação dos sujeitos que os documentos deixam entrever e que configura a EJA como um dispositivo de saber-poder, produzindo um sujeito educando híbrido na divisão entre duas modalidades de seres viventes, à Agamben (2014): um ser político, cidadão e alfabetizado, construído pelo discurso grafocêntrico da EJA; uma vida nua que a biopolítica deve açambarcar, domesticar, docilizar e civilizar.

Dessa perspectiva, pretendemos analisar dois discursos, quais sejam: o da qualificação permanente da mão de obra para o trabalho, por meio da educação formal; o da educação como mecanismo de acesso à cidadania ${ }^{2}$ e como transformação social. A hipótese é de que os documentos (tomados como monumentos arqueológicos, segundo Foucault na Arqueologia...) funcionam no interior de um dispositivo ainda excludente que, tal qual a descrição do dispositivo punitivo-prisional (e guardadas, certamente, as distinções, como se verá), operam segundo a ordem da normalização dos sujeitos, em

\footnotetext{
${ }^{1}$ Para boas discussões sobre Foucault e a educação, no Brasil, ver, por exemplo, Veiga-Neto (2014). Sobre a relação de Foucault e a modalidade EJA, ver: Martins (2006), Ramos (2013) e Andrade (2008).

${ }^{2}$ Os conceitos de cidadania - ou os seus deslocamentos -, neste trabalho, operam de forma a convergir com os discursos de promoção da escolarização de jovens e adultos como um direito. Pela análise histórica dos discursos, vê-se que o conceito de cidadania sempre se produz estrategicamente, conforme as condições históricas e socioeconômicas - e de acordo com as políticas estatais brasileiras. Os deslocamentos do conceito de cidadania são tratados na Seção 4 deste artigo.
} 
detrimento de supostos êxitos da ordem da "formação". Sua positividade, portanto, é aquela de um poder não de recusa e de repressão, mas de governo dos sujeitos e de disciplinarização. Digamos, de construção de formas de subjetividade codificadas.

Para tanto, o corpus de estudo selecionado para esta pesquisa reúne os seguintes documentos (monumentos discursivos): 1. a Resolução Municipal n.o 02, de 17 de dezembro de 2010, do Conselho Municipal de Educação; 2. a Lei Municipal n. ${ }^{\circ}$ 7.508/2007, de 31 de dezembro de 2007, que regulamenta, no âmbito do município de Florianópolis, o Sistema Municipal de Ensino; 3. e, por fim, aos eixos temáticos correspondentes à Educação de Jovens, Adultos e Idosos e à Educação Tecnológica e Formação Profissional, constantes no Plano Municipal de Educação (PME), de 2010. Todos eles são tidos como propostas permanentes, até agora, para a modalidade de EJA em Florianópolis.

A fim de defender a hipótese, na Seção 2, propomos uma 'discussão teórico-metodológica'; na seção seguinte, apresentamos um panorama breve dos discursos educacionais da escolarização de jovens e adultos no cenário brasileiro; e, por fim, produzimos uma análise dos discursos dos documentos sobre a EJA no âmbito florianopolitano.

\section{Poder, governo e dispositivo}

Neste trabalho, usaremos os ditos e escritos de Foucault para estudar o funcionamento da escolarização de jovens e adultos em Florianópolis como um dispositivo de controle sobre os educandos dentro do ambiente escolar, transformando-os em sujeitos socialmente dóceis; mais ainda: como a escolarização de jovens e adultos emerge, discursivamente, como Educação e alicerça-se na ideia de bem social.

Foucault, como é sabido, exige que se coloque em suspenso os instrumentos que considera eivados pela marca do antropologismo, "velhas questões de análise tradicional" (FOUCAULT, 2013b, p. 4), pois, antes, é preciso "libertar-se de todo um jogo de noções que diversificam, cada uma à sua maneira, o tema da continuidade" (FOUCAULT, 2013b, p. 25), como a de autor, obra, corpus, livro, tradição. Pelo contrário, é preciso conhecer as condições históricas que motivam tal ou tal tipo de conceitualização, é preciso ter uma consciência histórica da atual situação em que se vive (FOUCAULT, 2014b, p. 119). 
De um ponto de vista diferente em relação aos estudos da Análise do Discurso Francesa (BUTTURI JUNIOR, 2009), o francês produz suas análises a partir de uma discussão sobre os discursos e os enunciados. É na Arqueologia do Saber (AS) que o arqueologista amplia, reflete sobre e assenta esses instrumentos de/para descrição dos acontecimentos do discurso. Nessa AS, Michel Foucault problematiza as metodologias de pesquisa em ciências humanas: ele evidencia outras definições para seu instrumento de análise. Como conceito mais recorrente, Foucault (2013a, p. 131) determina discurso como "um conjunto de enunciados que se apoia em um mesmo sistema de formação", em um mesmo "conjunto de regras não estranho ao tempo para uma prática discursiva" (FOUCAULT, 2013a, p. 88), como um domínio imenso "constituído por um conjunto de enunciados efetivos (que tenham sido falados ou escritos), em sua dispersão de acontecimentos e na instância de cada um” (FOUCAULT, 2013a, p. 32), visto que, assim, é possível se falar sobre os diversos discursos, em suas específicas instâncias: o clínico, o acadêmico, o educacional, o psiquiátrico, o da história natural.

A problematização arqueológica dos discursos será retomada, a partir da década de setenta, segundo a urgência de se incluir uma discussão sobre o poder, suas táticas e estratégias. $\mathrm{O}$ poder, no entanto, não será tomado em sua substantividade, mas em seu caráter relacional e produtivo. Ele é uma “[...] rede produtiva que passa através de todo o corpo social ${ }^{3}$ muito mais que como uma instância negativa que tem como função reprimir” (FOUCAULT, 2014a, p. 16). Assim, com o poder, há mais relação com a produção de sujeitos do que efeitos de repressão. Nessa esteira, a produção das resistências, para Foucault, nada mais é que uma outra forma do poder se manifestar sobre os sujeitos. Logo, não existem sujeitos livres, mas controlados por relações de poder que exigem também relações de resistência. Assim, por meio dos efeitos diversos de poder, tem-se uma eficácia maior sobre o controle dos sujeitos, sobre a sua produção de subjetividade, sobre a docilização de seus corpos; tem-se menos dispêndios com procedimentos economicamente baratos, com resultados mais definidos, com menos possibilidades de escapatórias ou de resistências (FOUCAULT, 2013a, 2014a; MACHADO, 2015).

Uma das tecnologias principais da analítica desenvolvida pelo genealogista é o poder pastoral. Essa técnica de poder, segundo ele, surgiu das instituições cristãs, e diz respeito à série de procedimentos de governo dos indivíduos e dos corpos, na forma de uma

\footnotetext{
${ }^{3}$ Para Foucault (2014b, p. 135), “uma sociedade ‘sem relações de poder’ só pode ser uma abstração”.
} 
epimeleia ton allon. Nas aulas publicadas no texto Em defesa do sociedade, Foucault (2010) faz notar que é uma governamentalização dos Estados que marcará a modernidade e a contemporaneidade, segundo estratégias de produção de indivíduos em sujeitos em práticas de governo distintivas (disciplinas) e de acordo com técnicas de governo do corpo social, da população.

No Estado moderno, o novo poder pastoral, não mais como condução a uma salvação divina, funciona como uma garantia de salvação terrestre: "[...] saúde, bem-estar (isto é, nível de vida correto, recursos suficientes), segurança, proteção contra acidentes" (FOUCAULT, 2014b, p. 126). Ele, que antes estivera ligado a uma instituição religiosa (a Igreja), agora, segundo Foucault (2014b, p. 127) estendia-se "[...] ao conjunto do corpo social... [encontra] apoio em uma multidão de instituições", como as escolas, as polícias, a família, a medicina, os hospitais. Por fim, o objetivo desse novo poder centrarse-ia no desenvolvimento do saber em torno de pontos: "um, globalizante e quantitativo, dizia respeito à população; o outro, analítico, dizia respeito ao indivíduo" (FOUCAULT, 2014b, p. 127). Essa dupla relação entre corpo da população e corpo individual é que caracterizaria o biopoder nas sociedades modernas, onde o que está em jogo é o governo dos vivos (FOUCAULT, 2010).

O poder disciplinar, caro à escola e no interior das tecnologias de governo, emerge como um conjunto de procedimentos relacionados: ao desenvolvimento de aprendizagens e aptidões de sujeitos a serem disciplinados socialmente. O exercício do poder, assim, é positivo e produtivo, consistindo "[...] em 'conduzir condutas' e em arranjar a probabilidade. O poder, no fundo, é menos da ordem do enfrentamento entre dois adversários, ou do engajamento de um em relação ao outro, do que da ordem do 'governo"' (FOUCAULT, 2014b, p. 133).

É sob a égide de um dispositivo de governo, portanto, que parte este artigo para investigar os discursos da EJA em Florianópolis. Antes de passarmos às análises, porém, cabe fazer alguns apontamentos sobre o conceito de dispositivo.

\subsection{Os dispositivos e a sociedade do controle}

$\mathrm{O}$ conceito de dispositivo foi apresentado de forma bastante genérica em alguns textos de Foucault - como A Vontade de Saber (FOUCAULT, 2009) e em entrevistas, 
como a concedida à International Psychoanalytical Association, em 1977, em que ele discorre sobre o conceito como rede: “[é] um conjunto decididamente heterogêneo que engloba discursos, instituições, organizações arquitetônicas, decisões regulamentares, leis, medidas administrativas, enunciados científicos, proposições filosóficas, morais, filantrópicas. Em suma, o dito e o não dito são os elementos do dispositivo.” (FOUCAULT, 2009, p. 244). Um dispositivo seria uma rede complexa e relacional, constituída: de um campo de visibilidades, que permite fazer emergir objetos que se dão a ver conforme critérios específicos; de um campo de enunciações, que estratificam o visível em regimes de dizer possíveis; de linhas de força, relacionadas ao poder-saber e às estratégias e às urgências a que ele responde. Fundamentalmente, ainda, seriam solos de subjetivação, de produção de formas de subjetividade mais ou menos livres.

Agamben (2008) retoma a discussão dos dispositivos, deslocando-os a partir da contemporaneidade. Para ele (2009, p. 40), dispositivo é “[...] qualquer coisa que tenha de algum modo a capacidade de capturar, orientar, determinar, interceptar, modelar, controlar e assegurar os gestos, as condutas, as opiniões e os discursos dos seres viventes”. Assim, qualquer objeto, não somente a prisão, a escola, os sanatórios, poderiam se configurar como dispositivos, quando assim agirem. Essa ação, por sua vez, é o que Agamben relaciona, como faz Foucault, à noção de subjetivação. O sujeito, assim, é aquilo que está entre os seres viventes e os dispositivos. É o resultado “[...] da relação, por assim dizer, do corpo a corpo entre os viventes e os dispositivos". (AGAMBEN, 2008, p. 41).

Agamben (2009), deslocando Foucault, entretanto, assume que na atual fase do capitalismo as sociedades são controladas, não mais disciplinadas. Por essa recorrência, a noção de liberdade fecha-se paralelamente ao poder sobre os sujeitos. O que há, hoje, é um poder de controle, que atua estrategicamente e de forma espectral. Isso decorre, segundo ele (AGAMBEN, 2009, p. 48), devido a essas sociedades se apresentarem como “[...] corpos inertes atravessados por gigantescos processos de dessubjetivação que não correspondem a nenhuma subjetivação real”. Caberia, portanto, voltar-se a possibilidades de profanação e de resistência dos dispositivos, segundo táticas de deslocamento e de recriação de si mesmo - a tentativa, que aqui não poderá ser discutida, de um governo de si. Sob a égide do controle, Deleuze (1992, p. 215 et seq., grifos do autor), numa entrevista ao periódico Futur Antérieur, em 1990, afirma também que atualmente se trata de sociedades de controle, que operam não por confinamento, mas por comunicação, 
endividamento, formação continuada para o trabalho. O governo e suas tecnologias, no caso da escola, também sofrem um deslocamento nessas sociedades de controle e de puro governo.

É justamente na leitura da EJA como dispositivo de governo e de controle (produtor de objetivação e de formas de sujeito) que este artigo está alicerçado, conforme se poderá observar nas seções a seguir.

\section{$3 \mathrm{O}$ dispositivo da escolarização de jovens e adultos no brasil}

Falar de escolarização como dispositivo, sob uma perspectiva nacional e ampla, somente aquela destinada a jovens e adultos, exige que se retomem os deslocamentos históricos da formação de um discurso de nação para o Brasil. Segundo Haddad e Di Pierro (2000, p. 109, grifos nossos), “[...] a implantação de uma escola de qualidade para todos avançou lentamente ao longo de nossa história”. Passemos, pois, ao esforço de traçar um breve histórico, não exaustivo, a fim de marcar alguns deslocamentos estratégicos fundamentais na produção da escolarização do Brasil.

\subsection{Os discurso da escolarização para todos: da Colônia ao Império em panorama}

A formação dos saberes escolares no Brasil teve seu início já a partir do período colonial por meio da iniciativa da Igreja. Com os jesuítas, o principal objetivo pautava-se mais na catequese para os índios e colonizadores aqui residentes. Esse discurso colonial era da ordem de não valorização do saber escolar no espaço de terra brasilis. Além disso, a inserção de jesuítas, na Colônia, para catequizar os indígenas, partia da urgência histórica de inserir esses sujeitos numa ordem de Fé, Lei e Rei, como já premeditado na Carta de Pero Vaz de Caminha.

Como afirmam Severo e Makoni (2015), as práticas de letramento pautadas numa política linguística de crinstanletos produziram uma série de tecnologias educacionais na sociedade então majoritariamente oral, por meio da difusão de vários gêneros, que suplantavam a centralidade da religião numa educação voltada fundamentalmente aos gentios. A partir de 1768, com a chegada do Marquês de Pombal, os jesuítas foram expulsos da Colônia e teve-se uma reforma educacional no país. O Estado, mesmo ainda colonial, assumiu a responsabilidade da instrução escolar, “[...] cobrando um imposto, o subsídio 
literário, e introduzindo as aulas régias" (VILLALTA, 1997, p. 348, grifo do autor). Segundo Villalta (1997, p. 348), “[...] o ensino, do nível das primeiras letras ao secundário, passou a ser ministrado sob a forma de aulas avulsas, fragmentando o processo pedagógico". Além disso, os recursos orçamentários não eram suficientes para uma educação pública e a Coroa atrasava o salário dos mestres, quando já não havia falta deles, de manuais e de livros sugeridos pelos métodos de ensino da época.

A restrita formação escolar, desse modo, no período colonial, passou a ser encarada como algo a ser ostentado socialmente. Villalta (1997, p. 355) afirma que, após o florescimento de um discurso civilizatório e urbano, principalmente em Minas Gerais, a partir do século XVIII, a instrução, já restrita às elites, servia como abertura de portas para a conquista de cargos e "[...] sempre foi um apanágio dos privilegiados ou dos que podiam e almejavam ascender". Novamente, o ensino de língua surgiu como um dos enunciados centrais, cujos efeitos eram o de transformação do elemento indígena: "A língua portuguesa passou a ser oficialmente tomada como signo de civilidade e de superioridade, em oposição às culturas e línguas ditas primitivas" (SEVERO; MAKONI, 2015, p. 34).

É mister apontarmos a relação entre um discurso de civilidade e um discurso nacional-linguístico da reforma pombalina. Segundo Severo e Makoni (2015), formas de sujeito distintas foram produzidas a partir de um intrincado discurso linguístico, étnico e racial. Assim, era o "nível de proficiência" em Língua Portuguesa que passava a marcar os sujeitos; africanos e indígenas, nesse caso, ficaram circunscritos às línguas gerais e/ou incivilizadas. Contra a pluralidade das línguas e das práticas (orais ou escritas), assistiuse a "[...] implementação de um ideal lingüístico homogeneizador, tendente para o português europeu" (MATTOS E SILVA, 2004, p. 21), não obstante a ausência de uma estrutura educacional generalizada.

A formação escolar no Brasil, como dispositivo de Estado, somente entrou em vigor a partir da independência da Colônia em relação à Metrópole portuguesa, em 1822. De forma mais precisa, o discurso de uma "instrução da população brasileira" foi produzido com a promulgação da primeira Constituição do Império, em 1824. Nessa norma constitucional, como direito de todo cidadão, a escolarização era vista como instrução gratuita e, mesmo garantida a todos os brasileiros do Império, não era especificada a um público determinado (BRASIL, 1824). Essa garantia pública, entretanto, segundo Haddad e Di Pierro (2000), era admitida a uma pequena parcela da população, como já 
acontecia no período colonial: excluíam-se negros, indígenas e mulheres, e priorizava-se um discurso da cidadania - entendidos como cidadãos do Império os senhores pertencentes à pequena elite econômica do país -, circunscrevendo-se somente à formação de ofícios e à sobrevivência.

\subsection{A escolarização de jovens e adultos nas repúblicas: a multiplicidade dos discursos}

A instauração da República brasileira deu-se a partir da outorga da Constituição de 1891, primeiro marco legal que consagrou uma responsabilidade federal sobre o ensino básico. Entretanto, consoante ao que aconteceu no Império, a oferta de uma educação para as amplas camadas sociais marginalizadas não foi suficiente e houve, também, uma descentralização do papel de gerenciador das políticas educacionais. Semelhante ao que ocorre no período imperial, a União concedeu às províncias e aos municípios a responsabilidade pública pelo ensino aos seus cidadãos. Dessa forma, diante de uma política que vigorava de acordo com os interesses das oligarquias regionais, o ensino foi restrito a uma parcela da população economicamente privilegiada (HADDAD; DI PIERRO, 2000). A única ressalva, porém, estava na dissolução do Estado e Igreja como atores na formação escolar básica a todos. Se a República, a partir da Constituição de 1891, dizia-se laica, o discurso da Igreja já não entrava como alicerce da política educacional nacional.

Além disso, o papel de formação escolar foi adotado como um dispositivo de cidadania bastante específico: só poderiam votar aqueles que detinham formação escolar, garantindo a centralidade de uma política linguística que permanecia negando a oralidade, suplantando-a por um forte caráter elitista e grafocêntrico (BRASIL, 1891). Assim, quem não possuía uma formação escolar não tinha poder de voto, nem teria esse dispositivo de poder em suas mãos. Entretanto, quando se estabeleceu essa norma de exclusão, a população brasileira era iletrada - conforme mencionado anteriormente por Haddad e Di Pierro (2000), menos de um quinto na população brasileira com idade superior a cinco anos era letrada. Esse quadro, mesmo com uma preocupação maior da recente república em relação às reformas no ensino básico, segundo um censo de 1920, trinta anos após a proclamação, não se alterou consideravelmente.

O dispositivo político-educacional só começou a visar a formação escolar de jovens e adultos a partir da década de 1920, quando se comparou constantemente os índices 
precários de analfabetismo brasileiro em relação a outros países da América Latina e também ao restante do mundo (HADDAD; DI PIERRO, 2000). Assim, diante desse novo cenário socioeconômico do país (aumento do contingente populacional nos grandes centros urbanos, provocado principalmente pelo êxodo rural, e a modificação do espaço das cidades: grandes plantações de café deram lugar a avenidas, ruas e espaços destinados à implantação de fábricas, como em São Paulo), a República viu-se frente a uma modificação das políticas educacionais à grande massa populacional, até então analfabeta, que ocupava os centros urbanos (imigrantes, descendentes de escravos libertos, trabalhadores que seguiam o êxodo rural). O problema de ainda ter um contingente populacional urbano em grande parte formado de analfabetos trouxe ao Estado a necessidade de implantar especificamente modos de alfabetizar jovens e adultos que nunca tiveram formação escolar. Surge, assim, institucionalmente, um discurso sobre a escolarização de jovens e adultos, com o objetivo de ensinar os trabalhadores urbanos a ler, a escrever a fazer cálculos básicos. Nesse aspecto, há um deslocamento importante no dispositivo, no sentido de ampliação dos supostos educandos e, por conseguinte, segundo um novo discurso: a formação escolar passou de um privilégio elitizado para um direito comum a todos, principalmente aos trabalhadores industriais e de comércio nas cidades.

Durante a Era Vargas, através de um discurso político marcado pela amplificação dos direitos sociais da população, a partir da Constituição de 1934, a escolarização passou a receber uma atenção governamental: adotou-se a ideia de responsabilidade da União, dos estados e dos municípios, vinculou-se a manutenção e o desenvolvimento do ensino público, como também o dever estatal de entrega e cobrança dessas medidas políticas educacionais como direito amplamente direcionado a todos os brasileiros, inclusive e principalmente para jovens e adultos até então analfabetos.

Por meio desse reconhecimento constitucional e pela série de normas, órgãos e instrumentos dedicados à educação nacional, criou-se, em 1942, uma modalidade de ensino que era especificamente direcionada à população jovem e adulta: o Ensino Supletivo. A partir dessa política educacional, outros trabalhos para erradicar o analfabetismo no Brasil foram criados: em 1947, após o fim da Era Vargas, foi criado o Serviço de Educação de Adultos (SEA), cujo objetivo pautava-se na organização e manutenção dos serviços de ensino supletivos nos âmbitos estaduais e municipais (HADDAD; DI PIERRO, 2000, p. 
111; em 1952, a Campanha Nacional de Educação Rural; em 1958, a Campanha Nacional de Erradicação do Analfabetismo.

Por fim, entre 1959 e 1964, as políticas educacionais para a escolarização de jovens e adultos foram sumariamente intensificadas, visto que seu discurso de transformação social contribuía para a construção de discursos estatais voltados à transformação socioeconômica (PAIVA, 1994, p. 32). No chamado regime militar, houve novo deslocamento: instaurou-se uma cisão em relação às políticas educacionais. Como o voto não era mais observado, as políticas educacionais às faixas etárias foram exaustivamente minimizadas e novas modalidades de formação escolar aos jovens e adultos foram constituídas: as políticas foram extinguidas e ora passou-se a ministrar a formação cladestinamente, no que se chamou de "educação popular" (HADDAD; DI PIERRO, 2000, p. 112), ora por meio de ações assistencialistas, sem a necessidade de o Estado intervir na escolarização como um direito social.

Diante dessa necessidade do Estado em relação à permanência das políticas educacionais de jovens e adultos, fundou-se o Movimento Brasileiro de Alfabetização - o MOBRAL, em 1967, e o Ensino Supletivo, em 1971 - semelhante àquele de 1942 e que se extinguiria no final dos anos 1970 por uma série de críticas: o sistema de avaliação da aprendizagem não era confiável, o financiamento por parte do Estado não era muito claro em relação à sua execução e, além disso, a permanente modificação de seus objetivos e estrutura de formação concatenaram no seu fim.

Somente em 1971, com a consolidação da Lei de Diretrizes e Bases da Educação Nacional (LDB), de número 5.692/1971, a escolarização de jovens e adultos foi institucionalizada sobre a premissa do Ensino Supletivo. Pela LDB, a então formação escolar seria, pela primeira vez, especificadamente, regulamentada, i.e., apesar das constituições do Império e da República, nenhuma lei anteriormente regia de forma detalhada a então modalidade de ensino. Mesmo circunscrita num recorte histórico brasileiro de regime militar, o Ensino Supletivo seria a formalização da formação de saberes escolares de jovens e adultos como uma política de Estado e não somente como uma campanha governamental, ou um incentivo da Igreja, ou advindo da iniciativa privada.

O Ensino Supletivo, por sua vez, distanciava-se das experiências anteriores de formação escolar para jovens e adultos. Segundo Haddad e Di Pierro (2000, p. 117), “ [...] se produzia conforme um discurso reformador e propunha a recuperar o atraso, reciclar 
o presente, formando mão de obra que contribuísse no esforço para o desenvolvimento nacional, através de um novo modelo de escola”. Assim, essa modalidade de ensino ampliava “[...] a oferta de formação profissional para uma clientela já engajada na força de trabalho" (HADDAD; DI PIERRO, 2000, p. 117) e mostrava-se como um dos elementos promovidos pelo Estado condizendo com a modernização socioeconômica que o país vinha sofrendo nos anos 1970.

Tanto o MOBRAL quanto o Ensino Supletivo, dessa maneira, vinham sendo encarados como projetos que afirmavam a preocupação dos Estado com o discurso do desenvolvimento socioeconômico. Segundo Haddad e Di Pierro (2000, p. 118), a escolarização de jovens e adultos, nessa época, fora produzida segundo o viés do discurso desenvolvimentista: a formação de um Estado consolidado socioeconomicamente pautava-se na formação de uma classe trabalhadora alfabetizada e que não se manteria marginalizada na desigualdade, mantendo uma “[...] coesão entre as classes sociais" (HADDAD; DI PIERRO, 2000, p. 118). Por fim, um dos grandes problemas dessa suposta equalização social estava no fato dessas políticas educacionais do regime militar não serem exclusivamente do governo federal: a dissonância entre os poderes federal, estadual e municipal quanto à formação de sistemas de ensino promoveu uma divergência de objetivos e de programas coerentes ao público.

Com a redemocratização do país, a formação escolar, em todos os seus âmbitos, deixou de ser pautada num ideal nacionalista explícito e passou a subsistir sob a égide da inovação dos modos de ensinar e aprender, assim como também possibilitou a emergência da educação popular, antes clandestina aos olhos do Estado - e aqui podemos apontar, ainda, a importância dos discursos de resistência que partiam dos debates freireanos. Sobretudo a partir de 1996, no primeiro mandato do governo de Fernando Henrique Cardoso, a política educacional observou novos deslocamentos: houve uma priorização da “[...] implementação de uma reforma político-educacional da educação pública que compreendeu diversas medidas, dentre as quais a aprovação da emenda constitucional, quase que simultaneamente à promulgação da nova Lei de Diretrizes e Bases da Educação Nacional”, relatada por Darcy Ribeiro (HADDAD; DI PIERRO, 2000, p. 121). Entretanto, a escolarização de jovens e adultos, em 1996, já tão distante daquele cenário colonial, ainda permanecia ancorada num discurso tradicional de oferta pública e de exames supletivos. 
Em 1999, a partir das disposições que a LDB propunha, foi encaminhado ao poder público o Plano Nacional da Educação (PNE), projeto discutido desde 1997 pelo Ministério da Educação. No PNE, a escolarização de jovens e adultos foi entendida como formação educacional continuada ao longo da vida, entendida a partir de discursos produzidos segundo a ordem do direito à cidadania, propulsor para o desenvolvimento socioeconômico e instrumento de combate à pobreza. Haddad e Di Pierro (2000, p. 122, grifos nossos) apontam como estratégias do PNE “[...] resgatar a dívida social representada pelo analfabetismo, erradicando-o; treinar o imenso contingente de jovens e adultos para a inserção no mercado de trabalho; e criar oportunidades de educação permanente".

Diante dos discursos da globalização, e com um cenário econômico competitivo, a escolarização de jovens e adultos teve que remodelar seus conceitos e especializar a educação às necessidades e às demandas mercadológicas (PAIVA, 1994, p. 31). O dispositivo, nesse caso, deveria responder à urgência de um discurso do trabalho, da civilidade $\mathrm{e}$ da centralidade da proficiência em leitura e escrita, de ordem grafocêntrica e iluminista. ${ }^{4}$ A educação passa a ser entendida como “[...] instrumento de qualificação, de luta contra o desemprego e contra a marginalização" (PAIVA, 1994, p. 33).

Entretanto, o que se percebe é um novo deslocamento na importância da língua e uma maior preocupação com a formação de escrita e de leituras dos indivíduos, já que os avanços tecnológicos e as novas tecnologias exigem de todos, no mínimo, "[...] a capacidade de ler, de escrever e de manipular números de maneira eficiente" (PAIVA, 1994, p. 34). Como mecanismo de controle e de governo, os discursos de lifelong learning, da educação continuada de jovens e adultos, foi indispensável para reforçar a ideia de "qualificações-chave” (MERTENS apud PAIVA, 1994, p. 35). Portanto, a capacitação passa a ser vista conforme discursos de formação em várias categorias - da formação para o trabalho à formação "cidadã”, passando pela formação também da personalidade. Além de propriamente ensinar a ler e a escrever, os discursos elencados recortavam enunciados sociais e psicológicos, dando relevância à psicologia social e educacional. Para tanto, fica

\footnotetext{
4 Tomamos aqui grafocentrismo e sua relação com uma mitologia iluminista da educação conforme a discussão de Graff $(1990,1994)$.
} 
patente (tomado como exemplo as políticas europeias ${ }^{5}$ ), também a necessidade de criação de novas políticas educacionais como instrumento de um discurso de integração (PAIVA, 1994, p. 35).

\section{Os discursos da escolarização de jovens e adultos no sistema municipal de ensino de Florianópolis}

Quanto à entrada no novo século, a escolarização de jovens e adultos admitiu um novo discurso, porém não tão diferenciado daquele visado no fim do século $\mathrm{XX}$, principalmente a partir da outorga da Constituição de 1988, a “constituição cidadã”. Segundo Machado e Rodrigues (2013, p. 373), na entrada do século XXI, a educação, aqui circunscrita à escolarização de jovens e adultos, é um processo que acontece durante toda a vida de um sujeito e é dever do Estado garanti-la como direito a todo cidadão brasileiro.

Dessa perspectiva de uma educação como escolarização e como garantia de acesso à cidadania, o discurso que tomava forma era o do analfabetismo absoluto e funcional. Nesse caso, a não integralização da educação básica atingia todos os estratos da sociedade brasileira. Os dispositivos de governo faziam pulular as estatísticas de um suposto fracasso: conforme o Censo Demográfico de 2010 (IBGE, 2010), a população com idade superior a 15 anos somava 144,8 milhões de brasileiros, sendo que, desse contingente 65 milhões $(34,1 \%)$, ou não apresentava escolarização alguma ou possuía somente o Ensino Fundamental incompleto, e 27,5 milhões (14,4\%) não havia concluído o Ensino Médio.

A Educação de Jovens e Adultos (EJA), nesse aspecto, atuou, por meio de políticas públicas, como um dispositivo institucional de suposta inclusão desses sujeitos marginalizados pelo próprio Estado, permeada por um discurso assistencialista e compensatório produzido para a escolarização de sujeitos trabalhadores. Diante dessa formação histórica, além da existência da EJA enquanto modalidade calcada pela LDB de 1996, dois novos programas governamentais surgiram, na década de 2000, e atuaram como dispo-

\footnotetext{
${ }^{5}$ Paiva (1994, p. 35) cita, dentre os programas do EG-Task-Force (Human resources), lançado em 1990 pela União Europeia, o PETRA, que integrava os trabalhadores em círculos de conversa, controlando a qualidade do trabalho e, dessa forma, possibilitando "conhecer melhor as necessidades de qualificação" desses sujeitos. Outros programas integram, em sua amplitude, o EG-Task-Force (Human resources): Erasmus, Comett, Lingua, Tempus, Force e Eurotecnet.
} 
sitivos de suposta inclusão desses sujeitos diversos, num discurso de iluminismo pedagógico de ordem grafocêntrica que permanecia relacionando a educação e o trabalho sob o mesmo enunciado, a saber, o da profissionalização a sujeitos não escolarizados - e aí surgem o PROEJA (Programa Nacional de Educação Profissional Integrada a Educação Básica na Modalidade de Educação de Jovens e Adultos), em 2005, e o PRONATEC (Programa Nacional de Acesso ao Ensino Técnico e Emprego), em 2011.

Esse entendimento de como opera o EJA atual, enquanto um dispositivo de formação escolar, ora integrado à escolarização em si, ora sob uma perspectiva de qualificação profissional, pode, pois, também ser analisado na conjuntura do sistema municipal de ensino de Florianópolis, com base na constituição circunscrita e na regularidade que esse discurso da educação/trabalho. Essa escolarização de jovens e adultos em Florianópolis sofreu deslocamentos de acordo com as modificações nacionais, mas traçou itinerários próprios, segundo outra ordem de fatores políticos, sociais e culturais. Atualmente, no Plano Municipal de Educação (PME), aparece como uma modalidade de ensino integrada ao ensino fundamental, mas materializada como EJA, compreendida, porém, como a modalidade de ensino que atua no processo de escolarização para os florianopolitanos com idade superior a 14 anos não escolarizados ou quando não possuem a integral formação escolar compreendida para o Ensino Fundamental completo de 8 ou 9 anos.

Para fins de análise desse dispositivo, tomaremos os seguintes documentos: a Lei n. ${ }^{\circ}$ 7.508, de 31 de dezembro de 2007, aprovada pela Câmara Municipal de Vereadores na referida data; a Resolução do Conselho Municipal de Ensino CME n.o 02/2010, que passou a vigorar em 13 de dezembro de 2010; e, por fim, aos excertos que delineiam os dois eixos temáticos correspondentes, respectivamente, à Educação de Jovens e Adultos e à Educação Tecnológica e Formação Profissional, constantes no Plano Municipal de Educação (PME) de 2010.

A primeira norma “[...] regulamenta, no âmbito do município de Florianópolis, o Sistema Municipal de Ensino, de que trata a Lei Federal n. ${ }^{0} 9.394$ de 1996”. Essa lei, em seus 32 artigos, dispõe, especificadamente, sobre a organização, o funcionamento e a manutenção, no âmbito municipal, do ensino desde seus os níveis (da Ensino Infantil ao Fundamental) até às suas modalidades, que abrangem a educação de jovens e adultos e a educação especial. Quanto à resolução do Conselho Municipal de Educação, ela, especificadamente, "estabelece normas operacionais complementares em conformidade com 
o Parecer CNE/CEB n.o 06/2010, Resoluções CNE/CEB n..$^{\circ}$ 02/2010 e n.o 04/2010, que instituem as Diretrizes Gerais e Operacionais para a Educação de Jovens e Adultos” no Brasil. Os dois excertos, inclusos no PME, por fim, dizem respeito às diretrizes e metas da EJA e da formação tecnológica e profissional dos educandos de todo o Sistema Municipal de Ensino.

Passemos a algumas análises desses monumentos do dispositivo de escolarização da EJA em Florianópolis.

\subsection{Controle, trabalho e disciplina}

Partindo de uma análise sobre os discursos presentes nesses documentos, especificamente em relação à escolarização de jovens e adultos, vê-se que a educação, por meio do Sistema Municipal de Ensino, tem por finalidade, segundo o artigo $3^{\circ}$, inciso X, da Lei 7.508/2010 (FLORIANÓPOLIS, 2007, p. 1), o desenvolvimento do jovem e do adulto em relação à “[...] vinculação entre educação escolar, trabalho e práticas sociais”. Em consonância a isso, a Resolução CME n. ${ }^{\circ}$ 02/2010 (FLORIANÓPOLIS, 2010a), em seu artigo $2^{\circ}$, inciso $\mathrm{X}$, afirma que a Educação de Jovens e Adultos adota sua centralidade nos sujeitos educandos da modalidade, pressupondo, entre outros aspectos, o “[...] desenvolvimento de competências e habilidades para a inserção e a qualificação no mercado de trabalho. Além disso, o PME (FLORIANÓPOLIS, 2010b, p. 08 et seq.) assegura que estão inclusos, entre seus principais objetivos, “[...] a elevação global da taxa de escolaridade da população de Florianópolis..., [como também] a redução das desigualdades sociais e regionais, no tocante ao acesso e à permanência, na educação pública”.

Com suas diretrizes para a Educação de Jovens e Adultos, o PME pauta-se na promoção do discurso da educação como uma possibilidade para os sujeitos educandos partilharem das riquezas, inserindo-os no mundo do trabalho, por meio da "[...] oferta de cursos básicos de formação profissional no Ensino Fundamental” (FLORIANÓPOLIS, 2010b, p. 74) e promovendo a proteção contra o desemprego, por meio da articulação das políticas públicas de EJA e de geração de empregos (FLORIANÓPOLIS, 2010b)

Em relação a essa constituição dos sujeitos educandos de EJA, a Resolução CME n. ${ }^{\circ}$ 02/2010 considera os alunos de EJA já como sujeitos inseridos no mercado de trabalho, ou em vias de inserção, quando se deve considerar “[...] suas condições de vida e de 
trabalho" (FLORIANÓPOLIS, 2010a, p. 1, grifos nossos). O PME (FLORIANÓPOLIS, 2010b, p. 70, grifos nossos) afirma, diante disso, que os sujeitos se constituem não somente nos espaços de formação escolar, em processos contínuos de aprendizado, mas também "pelos múltiplos espaços sociais nos quais interagem, nas relações cotidianas da vida, como as do trabalho, da família, das associações, das igrejas etc.”. Além disso, “[...] a matrícula e a certificação dos estudantes da Educação de Jovens e Adultos poderão ser realizadas em qualquer época do ano" (FLORIANÓPOLIS, 2010a, p. 2) - esse último aspecto é admitido devido a um enunciado: o sujeito educando de EJA condiciona-se ao mundo do trabalho, i.e., sendo o trabalho uma das barreiras de escolarização, os educandos de EJA possuem essa liberdade de ingresso e formação ao longo do período letivo escolar da modalidade.

Um outro enunciado a ser considerado é em relação à idade dos educandos. Segundo o PME (FLORIANÓPOLIS, 2010b, p. 17), "a movimentação da população [de Florianópolis] apresenta características especiais, como, por exemplo, o aumento do número de habitantes na faixa etária dos 20 aos 29 anos". Em relação a isso, o PME vê a preocupação da escolarização desses sujeitos inseridos nessa faixa etária. Esse enunciado sobre quem é o sujeito educando de EJA é afirmado em todos os três documentos aqui analisados, visto que a idade mínima para a inserção na modalidade é de quinze anos (FLORIANÓPOLIS, 2007; 2010a; 2010b). Essa relação da idade mínima de inserção na EJA, assim, é condizente com a mesma faixa etária em que a População Economicamente Ativa é enunciada nos moldes nacionais em relação à escolarização de jovens e adultos (MACHADO; RODRIGUES, 2013, p. 377), fazendo funcionar o laço entre o discurso estatístico e os mecanismos de governamentalidade (FOUCAULT, 2010).

Há um discurso, em todos os três documentos, que afirma a relação entre escolarização e trabalho, principalmente devido aos sujeitos educandos de EJA possuírem características apresentadas de acordo com a definição de IBGE em relação ao PEA. O dispositivo de controle é relativo à produção de um sujeito trabalhador em constante formação (DELEUZE, 1992c): a EJA escolariza seus educandos, sujeitando-os, por meio de um discurso, ao mundo do trabalho; escolarizados, tornam-se economicamente viáveis, corpos dóceis e disciplinados para o trabalho segundo um discurso nacional-desenvolvementista - bastante recorrente na história da escolarização nacional, como se viu na seção anterior. 
Vamos adiante. Relacionando-se à EJA, o eixo temático correspondente à educação tecnológica e formação profissional, dentro do PME, atua como um dispositivo que visa a uma constante qualificação do trabalhador pelo viés da educação, porém de forma independente do ensino regular, visto sua importância nacional, como também visa promover a transição dos sujeitos educandos entre a escola e o mundo do trabalho. Entre as metas desse eixo temático, está a sua articulação com a EJA, “objetivando tanto a qualificação profissional para o trabalho quanto a elevação dos níveis de escolaridade dos trabalhadores" (FLORIANÓPOLIS, 2010b, p. 85).

Quando trata-se especificadamente da Educação de Jovens e Adultos, a Lei n.o 7.508/2007 (FLORIANÓPOLIS, 2007) apresenta da seguinte forma:

Art. 21. A educação de jovens e adultos será destinada àqueles com idade igual ou superior a quinze anos, que não tiveram acesso ou continuidade de estudos no ensino fundamental, na idade própria.

Art. 22. A educação de jovens e adultos deve:

I - desenvolver uma política de ingresso e permanência, mediante ações integradas e complementares entre si;

II - atender aos padrões definidos por lei e normas fixadas pelo Conselho Municipal de Educação;

III - garantir cursos com carga horária mínima presencial de setenta e cinco por cento do total previsto; e

IV - garantir um mínimo de duzentos dias de efetivo trabalho escolar.

À luz de Foucault (2013), o que podemos observar é uma “arte de distribuições” dos corpos dos sujeitos-educandos: a carga horária, a idade "própria”, a permanência, a produção de padrões e normas. Quanto ao controle, o que temos é a exigência de uma contínua qualificação para o trabalho, que pode ser verificada no artigo $5^{\circ}$ (FLORIANÓPOLIS, 2007) da Lei n. ${ }^{0}$ 7.508/2007, quando afirma ser dever do Estado a garantia de "formações suplementares" que independem da idade dos sujeitos. O que se vê é que os discursos dos documentos atuam como um dispositivo de controle sobre os sujeitos por meio de um enunciado que diz ser obrigatório o Ensino Fundamental. Mas ela também atua como um dispositivo de poder sobre o Estado, atribuindo a ele a promoção da escolarização de jovens e adultos de forma obrigatória e sem custos ao educando. Nesse as- 
pecto, a escolarização de jovens e adultos, por seu caráter legalista, difere daquela ocorrida no período colonial, imperial e alguns recortes da história republicana brasileira. Todavia, dispõe sobre o Estado uma obrigação: a de transformar a vida nua (AGAMBEN, 2014), de torná-la uma vida política, de acordo com critérios arbitrários restritos que, todavia, não prescindem de uma acuidade do governo disciplinar dos corpos.

É sobre essa hibridização do corpo do educando que versará a próxima subseção.

\subsection{Cidadania e vida nua}

No texto Homo Sacer, Agamben (2014) apresenta um debate sobre o que chama de "estrutura de exceção" da política ocidental, baseada na separação entre os viventes em dois tipos: aqueles que têm apenas a vida natural, zoé; aqueles que tem uma vida política, bíos. O italiano, ao observar essa distinção nos textos da Antiguidade, faz notar, a partir de Foucault e Arendt, que se trata de uma divisão ainda pertinente na política hodierna, desde a modernidade. Trata-se, conforme o debate da biopolítica, da produção de uma problemática da vida natural, nua, segundo as normas de uma vida política. O que esse discurso biopolítico traz é um regime de exceção em que a vida natural se torna uma questão. Na política moderna, é o corpo do homem que interessa, sua privacidade tornada pública, sua docilização. O Estado governamentalizado de Foucault, assim, mostra seu poderio como tecnologia de fazer viver e não deixar morrer aqueles que, a um só tempo, são uma vida biológica e uma vida cidadã.

A problematização de Agamben, certamente, não diz respeito à EJA ou particularmente às políticas linguísticas ou educacionais. No entanto, o problema biopolítico ligado à cidadania moderna pode ser profícuo para se pensar os discursos da EJA. Expliquemo-nos: no capítulo Os Direitos do Homem e a Biopolítica, o italiano traça comentários sobre as "Declarações”, notadamente sobre a Francesa, de 1789, trazendo à tona a relação entre a produção de Estados Nacionais e o investimento na transformação da vida nua para a vida político-cidadã. O limite entre o que chama de homens sacros (recuperado do homo sacer)- aqueles que podem ser mortos e que 
não merecem ritos de purificação - e os homens políticos, cidadãos de fato e de direito, seria o horizonte dos problemas do contemporâneo e da cisão entre os normais e os anormais, os trabalhadores e os desempregados, os cidadãos e os seres (apenas) naturais. Com Foucault (2010), a cisão de que trata Agamben opera estabelecendo limites entre certas raças e certas modalidades de sujeito. Note-se, ainda, que assim como em Foucault, o que se opera são separações não apenas raciais e étnicas, mas aquelas que dizem respeito a outras categorias: de sexo, de gênero, de classe etc.

Ora, no caso da EJA e dos documentos de Florianópolis, há uma série de enunciados que relacionam uma duplicidade: de um lado, aqueles que não têm as condições mínimas de desempenhar o papel de cidadãos, homens sacros cujo silêncio é construído segundo a oralidade e a exclusão da educação formal; do outro, o homem político, vida tornada bíos, que poderá definir-se como sujeito e cidadão de fato. Para os dois casos, uma série de procedimentos de disciplinarização e de controle, na busca de consolidar positivamente o regime grafocêntrico de exceção - que produz formas de sujeito mais ou menos legítimas, a partir da escrita.

Voltemo-nos aos documentos e à produção do sujeito cidadão. Vê-se que a modalidade de ensino, assim, apresenta um discurso de promoção da cidadania, da igualdade, da diversidade e compreensão do social externo aos espaços escolares. Segundo o artigo 20, da Lei n. ${ }^{\circ}$ 7.508/2007 (FLORIANÓPOLIS, 2007, p. 1), “[...] a educação é um processo de interação entre sujeitos, $[. .$.$] abrangendo a formação que$ se desenvolve [...] nos movimentos sociais, nas organizações da sociedade civil e nas manifestações culturais, políticas e religiosas”. Como se pode notar, a interação dos sujeitos está relacionada a deslocamentos: do povo ( e sua negatividade de vida nua atestada por Agamben) para a sociedade civil e suas práticas legítimas.

Como dever do Estado biopolítico, que exige uma formação para a cidadania, a EJA aparece no artigo 5o da Lei n. ${ }^{\circ}$ 7.508/2007 (FLORIANÓPOLIS, 2007, p. 2, grifos nossos):

IV - oferta de educação gratuita para jovens e adultos, equivalente ao ensino fundamental, garantindo condições de acesso e permanência; $\mathrm{V}$ - atendimento à criança, ao adolescente e ao adulto, por meio de programas suplementares.

$[\ldots]$ 
VII - padrões mínimos de qualidade estabelecidos em leis e atos normativos de qualidade.

O Ensino Fundamental, tarefa biopolítica estratégica do Estado, obedece aos padrões mínimos para a manutenção de uma vida política. As habilidades desse corpo dócil são tomadas como indispensáveis à vida social, por meio de um discurso de "liberdade de aprender, ensinar e pesquisar" (FLORIANÓPOLIS, 2007, p. 1) como uma educação continuada ao longo da vida, ou lifelong learning (PAIVA, 1994) das tecnologias do controle. A cidadania, ainda, exige que os sujeitos rompam com os limites da vida nua por meio da linguagem: não o discurso de uma voz desarticulada, mas o de uma fala estruturada por meio da alfabetização para uso social da escrita, da leitura e da numeração - i.e., de acordo com o modelo de letramento do sujeito educando de EJA. É apenas no escopo de uma educação formal que o sujeito passa às condições efetivas do discurso do sujeito político e pode, finalmente, exercer “plenamente sua cidadania” (FLORIANÓPOLIS, 2010b, p. 71).

Todavia, assim como acontecia com o dispositivo da prisão, citado no inícios deste artigo, os discursos sobre a educação também permanecem regidos pela lei do insucesso na série histórica e na produção de dados estatísticos, que estabelecem um déficit nos letramentos. Além disso, se como atesta Graff (1990), não é possível tecer relações diretas entre movimentos de alfabetização em massa e mobilidade social, o que existe, pelo contrário, é a manutenção de um dispositivo ainda excludente, no qual os pobres permanecem mais pobres, carregando, ademais, o ônus do que aqui poderíamos chamar de uma vida nua - completamente dispensáveis e incapazes de atualizar uma "efetiva" cidadania, porquanto pouco escolarizados e não devidamente disciplinarizados pelo regime grafocêntrico das políticas públicas.

Assim, alijados de uma vida política porque não alfabetizados ou produzidos como sujeitos apenas na condição de cidadãos referendados por um dispositivo de escolarização voltado a jovens e adultos, os sujeitos educandos da EJA apontam para o problema de inflacionar, como se percebe pelos excertos, o papel mitológico da soberania popular e do papel transformador da educação legados pelo Iluminismo. Por outro lado, o dispositivo de separação dessas formas de sujeito é efetivo e positivo quando minora as estratégias desse dispositivo pedagógico e suas implicações 
diretas no controle social (GRAFF, 1994, p. 91) da contemporaneidade governada e biopolítica.

\section{Considerações finais}

Neste trabalho, procurou-se analisar alguns discursos da EJA do município de Florianópolis. Procurou-se compreender a produção de um dispositivo no qual aparecem, estrategicamente, enunciados de formação de mão de obra escolarizada para o mercado de trabalho e enunciados de cidadania. Para tanto, por meio dos estudos de Michel Foucault, traçamos um breve panorama da constituição da escolarização de jovens e adultos na História do Brasil a fim de interrogar a permanência de um dispositivo grafocêntrico na EJA da capital catarinense.

Por fim, como em Vigiar e Punir, o que se observa é o poder positivo de um dispositivo que cria formas de sujeito específicas, o cidadão e o trabalhador, não obstante as dificuldades e as críticas de se forjar um "efetivo" processo de formação. Certamente, a efetividade estratégica do poder opera, nos dispositivos educacionais das tecnologias de governo, segundo outra ordem: a da cisão entre formas de sujeitos viventes e, no limite, ainda de acordo com a exclusão, pautada agora no grafocentrismo e na exigência de uma formação continuada e controlada para o trabalho.

Como dispositivo de governo do Estado, então, a escolarização de jovens e adultos por toda a história brasileira mostra o privilégio do poder estatal na constituição de uma diferença - repitamos, cara ao poder positivo e biopolítico. Baseada num discurso de universalização da educação e num mito da educação como mecanismo de cidadania, a EJA surge como um dispositivo ainda problemático, às voltas com o esforço diário de educar e formar sujeitos e, na multiplicidade relacional em que se implica, cindindo os mesmos sujeitos em modalidades desiguais de participação na vida política e de acordo com procedimentos cada vez mais delicados e infinitesimais de controle, disciplina e governo. 


\section{Referências}

AGAMBEN, G. O que é o contemporâneo e outros ensaios. Chapecó: Argos, 2008. .Homo sacer: o poder soberano e a vida nua I. Trad. Henrique Burigo. 2.ed. Belo Horizonte: Editora UFMG, 2014.

ANDRADE, S. dos S. Juventudes e processos de escolarização: uma abordagem cultural. 2008. Tese (Doutorado em Educação) - Universidade Federal do Rio Grande do Sul, Faculdade de Educação, Programa de Pós-Graduação em Educação, Porto Alegre, 2008.

BRASIL. Constituição (1824). Constituição Política do Império do Brasil: elaborada por um Conselho de Estado e outorgada pelo Imperador D. Pedro I, em 25.03.1824. Rio de Janeiro: 1824. Disponível em:

http://www.planalto.gov.br/ccivil_03/Constituicao/Constituicao24.htm. Acesso em: 07 jul. 2016.

. Constituição (1891). Constituição da República dos Estados Unidos do Brasil (de 24 de fevereiro de 1891). Rio de Janeiro: 1824. Disponível em:

http://www.planalto.gov.br/ccivil_03/Constituicao/Constituicao91.htm. Acesso em: 07 jul. 2016.

BUTTURI JUNIOR, A. Metafísica e discurso: Pêcheux, Foucault e a pós-modernidade. São Carlos: Pedro e João Editores, 2009.

DELEUZE, G. Conversações. São Paulo: Ed. 34. 1992.

FLORIANÓPOLIS (Município). Câmara Municipal de Vereadores. Lei n. ${ }^{\circ}$ 7.508/2007, de 31 de dezembro de 2007. Dispõe sobre a Organização, o Funcionamento Manutenção do Sistema Municipal de Ensino de Florianópolis. Florianópolis: 2007.

. Conselho Municipal de Educação. Resolução n. ${ }^{\circ}$ 02/2010, de 17 de dezembro de 2010. Estabelece normas operacionais complementares em conformidade com o Parecer n. 06/2010, Resoluções CNE/CEB n.o 02/2010 e n. ${ }^{\circ}$ 04/2010, que instituem as Diretrizes Gerais e Operacionais para a Educação de Jovens e Adultos. Florianópolis: 2010a.

- Secretaria Municipal de Educação. Plano Municipal de Educação de Florianópolis. Florianópolis: 2010b.

FISCHER, R. M. B. Foucault revoluciona a pesquisa em educação? Perspectiva, Florianópolis, v.21, n.02, p. 371-389, jul./dez. 2003.

FOUCAULT, M. História da sexualidade I: a vontade de saber. Rio de Janeiro: Edições Graal, 2009.

. Em defesa da sociedade - curso no Collège de France, 1975-1976. Trad. Maria Ermantina Galvão. 2.ed. São Paulo: Martins Fontes, 2010. 
. Vigiar e punir: nascimento da prisão. Petrópolis: Vozes, $2013 a$.

. A arqueologia do saber. 6. ed. Rio de Janeiro: Forense Universitária, 2013b.

. Entrevista com Foucault. In: . Ditos e escritos, volume IX: genealogia da

ética, subjetividade e sexualidade. Rio de Janeiro: Forense Universitária, 2014a. p. 13-34.

. O sujeito e o poder. In: . Ditos e escritos, volume IX: genealogia da ética, subjetividade e sexualidade. Rio de Janeiro: Forense Universitária, 2014b. p. 119-140.

. Microfísica do poder. Rio de Janeiro: Paz e Terra, 2015.

GRAFF, H. J. O mito do alfabetismo. In: Teoria \& Educação. Porto Alegre, n. 2, p. 36-64, 1990.

- Passado e presente da alfabetização: abordagens críticas sobre a relação alfabetização/sociedade. Tradução de Tirza Myga Garcia In: Os labirintos da alfabetização: reflexões sobre o passado e o presente da alfabetização. Porto Alegre: Artes Médicas, 1994.p.65-94.

HADDAD, S.; DI PIERRO, M. C. Escolarização de Jovens e Adultos. Revista Brasileira de Educação, São Paulo, n. 14, p. 108-131, maio/ago. 2000.

INSTITUTO BRASILEIRO DE GEOGRAFIA E ESTATÍSTICA. Censo Demográfico 2010: trabalho e rendimentos - resultado da amostra. Rio de Janeiro: Ministério do Planejamento, Orçamento e Gestão, 2010.

MACHADO, R. Por uma genealogia do poder. In: FOUCAULT, Michel. Microfísica do poder. Rio de Janeiro: Paz e Terra, 2015. p. 07-34

MACHADO, M. M.; RODRIGUES, M. E. de C. Educação de jovens e adultos: relação educação e trabalho. Retratos da Escola, Brasília, v. 7, n. 13, p. 373-385, jul./dez. 2013.

MARTINS, A. P. A escola, a ruptura, o retorno: a educação de jovens e adultos. 2006. Dissertação (Mestrado em Educação) - Programa de Pós-Graduação em Educação, Universidade de Blumenau, Blumenau, 2006.

MATTO E SILVA; R. V. Ensaios para uma sócio-história do português brasileiro. São Paulo: Parábola, 2004.

PAIVA, V. Anos 90: as novas tarefas da educação dos adultos na América Latina. Cadernos de Pesquisa. n. 89, São Paulo, p. 29-38, maio 1994.

RAMOS, F. de O. Representações de escola por alunos evadidos e reinscritos em turmas de Educação de Jovens e Adultos (EJA). Dissertação (Mestrado em Educação) Universidade de Taubaté, Programa de Pós-Graduação em Linguística Aplicada, Taubaté, 2013.

SEVERO, C. G.; MAKONI, S. Políticas linguísticas Brasil-África: por uma perspectiva crítica. Florianópolis: Insular, 2015. 
VEIGA-NETO, A. Foucault e a educação. 3 ed. Belo Horizonte: Autêntica Editora, 2014. VILLALTA, L. C. O que se fala e o que se lê: língua, instrução e leitura. In: SOUZA, L de M; NOVAIS, F. A. (Org.). História da vida privada no Brasil.v. 1Rio de Janeiro: Cia. das Letras, 1997.p. 331-384.

Data de submissão: 06/08/2016

Data de aceite: 16/08/2016 